\title{
Muerte artera, crimen político
}

Reseña: Valenzuela, José Manuel (2019) Trazos de sangre y fuego. Bionecropolítica y juvenicidio en América Latina Quito: FLACSO/ Centro Maria Sibylla Merian de Estudios

\section{Jorge Daniel Vásquez}

"[... los padres de la clase obrera
moderna empezaron viéndose castigados
por algo de que ellos mismos no eran víctimas,
por verse reducidos a vagabundos y mendigos"
Karl Marx, El Capital I ${ }^{1}$

C eñala Marx ([1867] 1977, 624-625) que la acumulación originaria del capital en Europa (a fines del siglo XV y a lo largo del XVI) implicó la creación de leyes que persiguieran "a sangre y fuego" a las masas que, una vez expulsados de sus tierras, recibieron el nombre de 'vagabundos' en el orden del nuevo estado. Tal violencia es equivalente al asesinato no sólo revestido de castigo público sino como correlato de proyectos generadores de desigualdad.

En Trazos de sangre y fuego. Bionecropolítica y juvenicidio en América Latina, el sociólogo mexicano José Manuel Valenzuela analiza la configuración que la relación vida-muerte adquiere en el capitalismo del siglo XXI. En el análisis del autor, tal configuración integra el asesinato, especialmente de jóvenes y mujeres, como expresión límite de

\footnotetext{
* Co-director editorial de Theorein. Revista de Ciencias Sociales. https://orcid.org/0000-0002-4716-768X. Email: theoreineditor@puce.edu.ec

${ }^{1}$ Marx ([1867]1977, 625). El énfasis (K) es mío.
} 
la biopolítica; la adulteración de las instituciones; y la precarización, en el marco de la economía política regional.

La violencia manifiesta en éstos tres fenómenos descubre los rasgos mórbidos del capitalismo. No se trata de un descubrimiento producto de sacar a la luz la violencia que habita en los espacios privados, sino de la exhibición pública del asesinato. Si bien Foucault (1978) había anunciado el fin del castigo público y su traslado al ámbito de la microfísica, la exhibición pública del asesinato replantea el objetivo aleccionador del suplicio de Damiens más allá de los actos directos del Estado, un suplicio público cometido por el narcotráfico y el crimen organizado en complicidad con figuras institucionales.

Paradójicamente, el suplicio público complementa su exhibición en el hallazgo de fosas clandestinas, como en el caso de Colombia y México. ${ }^{2}$ Los testimonios de sobrevivientes dicen de "relatos de vivencia extrema" que, en sus propias palabras, operan como forma de "exorcizar los recuerdos" (Valenzuela 2019, 30-34; 37-49).

La exhibición pública de los rasgos mórbidos del capitalismo puede también leerse dentro de una voluntad de espectacularización que no pretende convertir al otro en objeto de consumo (Hall 1997), sino en un ser despojado de la condición mínima de otredad: la vida y el rostro (Valenzuela 2019, 38-40). Despojadas de su vida son no sólo los muertos, sino los “niños adultecidos que interiorizan los códigos de muerte del narco-mundo" y que trabajan como escuadrones de defensa de un espacio donde el crimen organizado ejerce una suerte de "gobierno privado indirecto" (Mbembe 2015, 67-94). Esos niños, serán construidos como cuerpos desechables, un día victimarios y siempre potenciales víctimas de la muerte artera.

2 El autor cita el Informe de la Comisión Nacional de Derechos Humanos de 2017, que señala que entre 2007 y 2016 fueron halladas en México 855 fosas clandestinas con un total de 1548 cadáveres. 
Valenzuela ha acuñado y promovido el uso heurístico del concepto “juvenicidio" con cuatro objetivos que se pueden sintetizar así: 1) señalar y visibilizar la muerte artera e impune sobre juventudes precarizadas, 2) hacer visibles pertenencias, adscripciones y repertorios que incrementan posiblidades de que un joven sea asesinado, 3) el desarrollar estrategias de orden académico y político orientadas a impedir la continuación de asesinatos de jóvenes, 4) identificar causas y responsables de tanta muerte innecesaria (Valenzuela 2019, 61).

Su concepto nació vinculado al de 'feminicidio' en su análisis sobre jóvenes en la frontera entre México y Estados Unidos ${ }^{3}$, y se vuelve fundamental a partir de la "guerra contra el crimen organizado" iniciada en la presidencia de Felipe Calderón (2006-2012) y que entre 2006 y 2014 había dejado ya un saldo de 164.345 asesinatos. Sólo en 2013, fallecieron 34.509 jóvenes. En 2014, los principales tipos de muerte violenta en México fueron: agresión con disparo de arma de fuego (11.641), agresión con objeto cortante (2.902), agresión por ahorcamiento, estrangulamiento y sofocación (1.343) sin diferencia de género en el orden de los tipos de violencia (Valenzuela 2019, 53-58).

El concepto "juvenicidio" dice de la situación descrita en el párrafo anterior, pero requiere, como el mismo autor plantea, de la problematización de las formas de control del cuerpo de los jóvenes desde la regulación de la sexualidad y la penalización del aborto, hasta los patrones estéticos que instauran marco prohibicionistas de la significación corporal. La violencia que acompaña este tipo de control dice de su carácter no sólo biopolítico sino necropolítico: un poder sobre la muerte que, para el autor, va desde la precarización hasta la aniquilación. Por ejemplo, la violencia sexual y la

3 Valenzuela (2012) realizó un estudio sobre el feminicido en su libro Sed de Mal. Feminicidio, jóvenes y exclusión social. México: El Colegio de la Frontera Norte 
explotación, de la cual son víctimas especialmente los y las jóvenes, dice de la conjunción de repertorios de precarización (precarización económicasocial, desacreditación identitaria) que producen zonas habitas por sujetos descartables. Quizá tales repertorios de precarización no son sino la antesala y la justificación de una forma de 'acumulación por aniquilamiento' (Bosteels 2018).

Para Valenzuela, la precarización genera la condición de iuvenis sacer (una particularidad dentro de la condición de homo sacer -i.e., Agamben) para aquellos que habitan en las zonas de precarización (o necrozonas) creadas por el capitalismo. Este señalamiento de Valenzuela representa un punto fundamental para una aproximación crítica a los estudios sobre juventud que otorgan a esta condición unas características descontextualizadas y asociadas al consumo de bienes simbólicos globales. ${ }^{4}$

Si el análisis del juvenicidio incluye necesariamente el problema de la muerte entre jóvenes (en mayor número son jóvenes los que matan jóvenes) hablamos entonces de que las identidades juveniles no son sólo resultado de una apropiación de insumos provenientes de la industria cultural (por más crítica desde su performance o parámetros de negociación), sino de la subjetivación-objetivación conflictiva de condiciones sociales, económicas y (geo)políticas.

\footnotetext{
4 Así lo expresa claramente Valenzuela $(2019,70)$ al decir: "He insistido en la vacuidad de los conceptos de lo joven o lo juvenil, fuera de los cronotopos que le significan, en otras palabras, no podemos hablar del joven fuera del contexto histórico social, las relaciones situadas, los entramados relacionales y las adscripciones identitarias que le definen”. En mi lectura, esta declaración apunta a trabajos que, amparados en una juvenilización de la cultura, fortalecieron una concepción que borraba las diferencias de clase, etnia y nacionalidad entre los distintos grupos juveniles (para un ejemplo ver Montesinos 2009), lo cual constituye un aspecto central en el balance de la producción académica en estudios sobre juventud en el siglo XXI. Para una visión crítica de los estudios sobre juventud desde la cuestión de clase ver Duarte (2006), la cuestión étnica en Vásquez (2014), y de género y clase en Serrano (2004).
} 
Pero tales diferencias no son sólo resultado de una agregación identitaria, sino que son creadas y asignadas desde el poder diferenciador que acentúa la desigualdad y su racialización. El caso de 'los mirreyes' (Valenzuela 2109, 76-89) puede ser leído como una muestra de esto. Para el autor, "los mirreyes son jóvenes que integran de manera simbiótica aspectos definitorios de los identificadores de clase de los juniors, esos jóvenes ricos e influyentes que ostentan privilegios y carisma derivado del poder de papi" (Valenzuela 2019, 79). Esto explica el grito de los ciudadanos de Zacatecas, "Ni reyes, ni mirreyes", ante la visita del Rey Felipe VI de España y presidente Enrique Peña Nieto en julio de 2015 a ese lugar.

En síntesis, los mirreyes representan la confluencia de dos fenómenos. Por un lado, constituyen la antípoda de las vidas precarias de millones de jóvenes, "estereotipados, proscritos y criminalizados" (Valenzuela 2019, 89), a la vez que representan la recreación de los "discursos clasistas y racistas de los poderosos" (íbid). Así, los mirreyes (una suerte de updated version del 'pirruris' de Luis del Alba), utilizan expresiones como 'naco' (quizá proveniente de 'totonaco', término referente a los pueblos indios que habitan la región de Veracruz), 'prole' (expresión para referirse despectivamente al 'proletariado', en general a las personas trabajadoras y asalariadas), o 'chairo'. "Chairo conlleva una carga de desprecio, de ofensa, de subestimación, de menosprecio [...] se utiliza con un sentido racista y clasista para identificar a la izquierda prole, naca, chúntara, chola, jodida, y la oscuridad epidérmica [...]" (Valenzuela 2019, 85).

Así, los mirreyes constituyen un motor de la precarización simbólica desde la racialización de los pobres; pero quizá el análisis de Valenzuela abre la posibilidad para pensar la blanquitud (o los actores de la blanquitud) como minoría, agrupados en torno a sus propios mitos y rituales violentos. 
Otra línea de análisis abierta por Valenzuela, desde su amplio recorrido en estudios culturales, juventud, y estudios de frontera, es la formulación de conceptos como biocultura y biorresistencia. Para el autor, tanto la biopolítica (Foucault 2010), como la necropolítica (Mbembe 2003) refieren a un poder unidireccional; mientras que biocultura refiere a "la centralidad corporal que media procesos sociales [...] la aceptación y el desafío de los dispositivos, estrategias y postulados normalizadores de la biopolítica" (Valenzuela 2019, 90), y la biorresistencia se expresa en las respuestas individuales y colectivas frente a la bio-necro-política.

De este modo, mientras el Estado, el crimen organizado, o la industria cultural, produce cuerpos juveniles monstrificados, Valenzuela ve en los movimientos sociales de este siglo (Primavera Árabe, Indignados 15M, \#YoSoy132, Mesa Amplia Nacional Estudiantil, La Revuelta) un fuerte protagonismo juvenil que no sólo plantea horizontes alternativos, sino que integra un despliegue emocional, una política bio-emocional.

Queda aún por construir la tarea analítica en torno a la política bioemocional integrada en proyectos políticos transclasistas e interraciales. Tal como la antropóloga mexicana Maritza Urteaga y Hugo César Moreno (2015) han planteado, el punto crucial del vínculo entre precarización y juvenicido es la "des-ciudadanización". Si bien los movimientos sociales de protagonismo juvenil integran una condición emocional que sugiere nuevos horizontes de posibilidad, no es menos cierto que estos horizontes replantean un discurso en torno a derechos, una ampliación de la ciudadanía y un ejercicio de ésta aún en contra de los mecanismos que la capturan, por medio del juvenicidio, a favor del poder despótico. Así, el texto de Valenzuela no sólo llama la atención sobre la particularidad del fenómeno de la violencia, sus trazos de sangre y fuego sobre la vida de los pobres, 
los subalternos y los y las jóvenes, sino que constituye un aporte clave para pensar el juvenicidio y el feminicido, la muerte artera, como el crimen político por excelencia del capitalismo de este siglo.

\section{Referencias}

Bosteels, B. (2018). From Ayotzinapa to Tlatelolco: A Memorial of Grievances against the State. Scienza \& Politica, XXX(59), 41-60.

Duarte, K. (2006). Discurso de resistencias juveniles en sociedades adultocéntricas. San José: DEI.

Foucault, M. (1978). Vigilar y Castigar. El nacimiento de la prisión. Buenos Aires: Siglo XXI.

Foucault, M. (2010). El nacimiento de la biopolítica. Buenos Aires: FCE.

Hall, S. (1997). The Spectacle of the 'Other'. In Stuart Hall (ed)., Representation: Cultural Representations and Signifying Practices (pp. 223-279). London: Sage.

Marx, K. ([1867]1977). El Capital. Crítica de la Economía Política. México: FCE.

Mbembe, A. (2003). Necropolitcs. Public Culture, 15(1), 11-40.

Mbembe, A. (2015). On the Postcolony. Johannesburg: Wits University Press.

Montesinos, D. (2009). La juventud domesticada. Cómo la cultura juvenil se convirtió en simulacro. Madrid: Editorial Popular.

Serrano Amaya, J. F. (2004). Menos querer más de la vida. Concepciones de vida y muerte en jóvenes urbanos. Bogotá: Siglo del Hombre/Fundación Universidad Central. 
Urteaga, M., \& Moreno, H. C. (2015). Corrupción e impunidad versus Justicia y Derecho en México. In J. M. Valenzuela (coord.), Juvenicidio. Ayotzinapa y las vidas precarias en América Latina y España (pp. 79-98). Barcelona: NED.

Vásquez, J. D. (2014). Identidades en transformación. Juventud indígena, migración y experiencia transnacional. Quito: FLACSO/Université Catholique de Louvain/Universite de Liège.

Valenzuela, J. M. (2019). Trazos de sangre y fuego. Bionecropolítica y juvenicidio en América Latina. Quito: FLACSO/ Centro Maria Sibylla Merian de Estudios Latinoamericanos Avanzados en Humanidades y Ciencias Sociales-CALAS.

Valenzuela, J. M. (n.d.). Sed de Mal. Feminicidio, jóvenes y exclusión social. México: El Colegio de la Frontera Norte. 